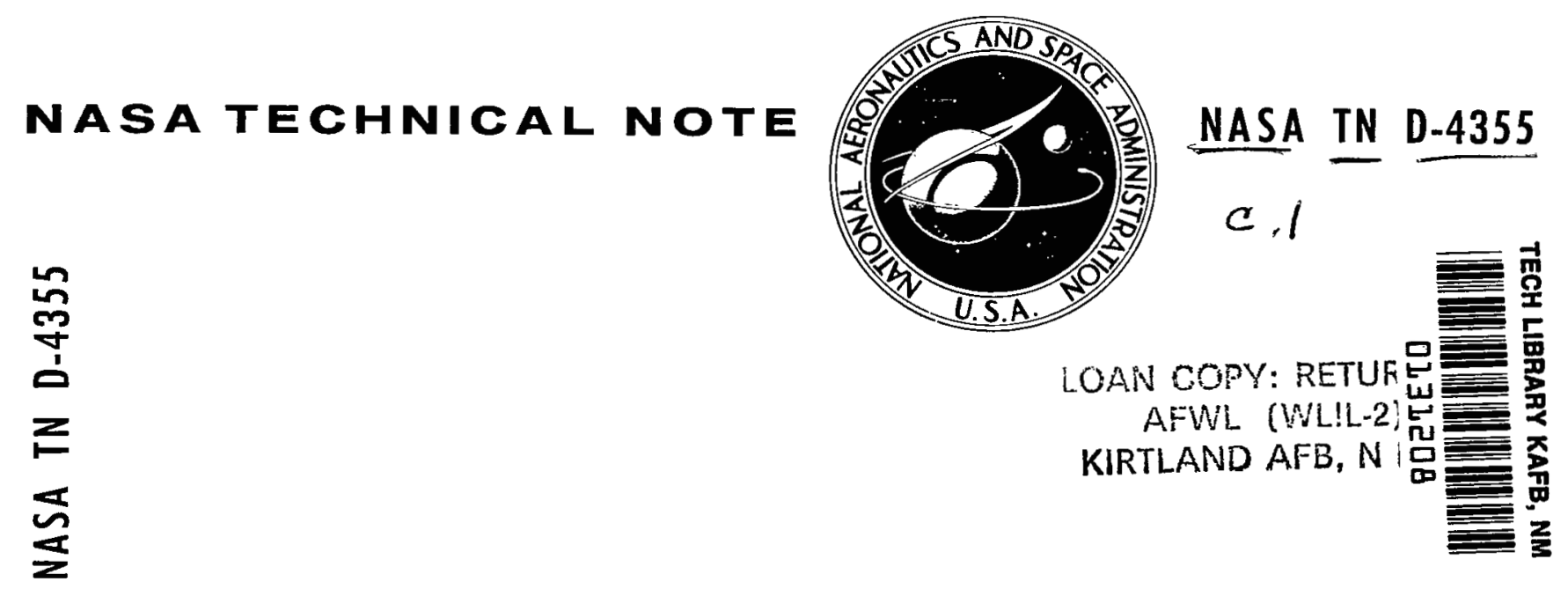

FRICTION TORQUE OF BALL BEARINGS

IN VACUUM WITH SEVEN

POLYTETRAFLUOROETHYLENE-COMPOSITION RETAINER MATERIALS

by Herbert W. Scibbe, Dean C. Glenn, and William J. Anderson

Lewis Research Center

Cleveland, Obio

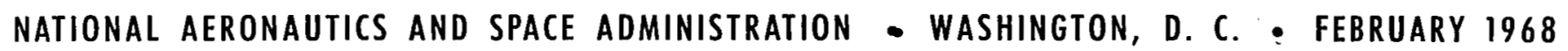


FRICTION TORQUE OF BALL BEARINGS IN VACUUM WITH SEVEN POLYTETRAFLUOROETHYLENE-COMPOSITION RETAINER MATERIALS

By Herbert W. Scibbe, Dean C. Glenn, and William J. Anderson Lewis Research Center Cleveland, Ohio

\section{NATIONAL AERONAUTICS AND SPACE ADMINISTRATION}

For sale by the Clearinghouse for Federal Scientific and Technical Information Springfield, Virginio 22151 - CFSTI price $\$ 3.00$ 


\title{
FRICTION TORQUE OF BALL BEARINGS IN VACUUM WITH SEVEN
}

\section{POLYTETRAFLUOROETHYLENE-COMPOSITION}

\author{
RETAINER MATERIALS \\ by Herbert W. Scibbe, Dean C. Glenn, and William J. Anderson \\ Lewis Research Center
}

\section{SUMMARY}

Self-lubricating retainer materials containing various weight percentages of polytetrafluoroethylene (PTFE), glass fibers, molybdenum disulfide $\left(\mathrm{MoS}_{2}\right)$, and bronze were evaluated in 20-millimeter-bore ball bearings operating in a vacuum of $10^{-6}$ torr $\left(1.33 \times 10^{-4} \mathrm{~N} / \mathrm{m}^{2}\right)$. The lubricating capability of the retainer materials was evaluated by measurement of the bearing friction torque. The test bearings were run at $3600 \mathrm{rpm}$ with axial loads from 35 to 100 pounds (156 to $445 \mathrm{~N}$ ) for periods of approximately 1 hour.

Although all retainer materials lubricated the bearings reasonably well, the best lubrication, as measured by the lowest average friction torque, was obtained with a bearing equipped with a retainer of 70 percent PTFE, 15 percent glass fibers, and 15 percent $\mathrm{MoS}_{2}$. In an initial run at a load of 50 pounds $(222 \mathrm{~N})$ with this material, the bearing torque was high and erratic; in the next three consecutive runs, however, the torque remained at a low, constant level. This behavior indicated that a run-in period was required before good lubrication of the bearing could be achieved. In the following three consecutive runs, the bearing registered low, steady torque upon restart and thereby demonstrated good restart capability. During the time intervals of 24 hours or more between the runs, the bearing "soaked" in the vacuum chamber. The good performance with this retainer was partly attributed to a fabricating process that produced a homogeneous mixture of PTFE, glass fibers, and $\mathrm{MoS}_{2}$ in the material.

Bearing torque was not markedly changed by the addition of 5 percent $\mathrm{MoS}_{2}$ to glassfiber-filled PTFE materials. Bearings with bronze-filled PTFE retainers had approximately the same torque levels as the other filled PTFE materials. No benefit in heat dissipation from the bearings was noted for the bronze-filled PTFE retainers run in this investigation.

Although the 100-percent-PTFE retainer produced low bearing torque, the wear rate of this material was unacceptably high. 


\section{INTRODUCTION}

Rolling element bearings are required in spacecraft and satellite mechanical systems to support and to locate accurately the rotating or oscillating components of these systems. Although these systems may be subjected to high static forces during the launch operation, the inertial loads on the bearings are negligible when the vehicle has achieved orbit and the mechanisms are operating in a zero-gravity environment. Bearing dynamic loads, however, such as those resulting from power transmission forces, will be present. If rigidity in the bearing supports and location accuracy of the components are required, the bearings must be preloaded when they are assembled in the system.

Effective lubrication of the bearings in these mechanisms may be provided by a selfcontained system, wherein the bearing retainers function as the lubricant reservoir. The retainers may be either impregnated with liquid lubricants or fabricated from solid self lubricating materials (refs. 1 and 2). Because liquid lubricants have comparatively high evaporation rates (refs. 3 and 4), they may not be as desirable for some space applications as solid lubricants. Direct exposure of the bearings to the low pressures of space would result in excessive evaporation of the lubricant. The lubricant system may therefore require containers, baffles, or labyrinths to restrict the evaporative loss. The evaporation of the lubricant and its subsequent condensation on nearby instrument components may obscure light transmission through optical surfaces and provide conductive paths that may cause short circuits in electronic components (ref. 5).

Solid lubricants such as polytetrafluoroethylene (PTFE) and molybdenum disulfide $\left(\mathrm{MoS}_{2}\right)$ have evaporation rates lower than liquid lubricants above $350^{\circ} \mathrm{F}\left(450^{\circ} \mathrm{K}\right)$ at ambient pressures of about $10^{-6} \operatorname{torr}\left(1.33 \times 10^{-4} \mathrm{~N} / \mathrm{m}^{2}\right)$ (ref. 3). These lubricants have effectively lubricated surfaces exposed to vacuum.

Several investigators have successfully run self-lubricating, filled PTFE materials in vacuum, both in friction and wear experiments (ref. 6) and in full-scale ball bearings (refs. 5 and 7). In reference 6 friction and wear data are given for filled and unfilled PTFE riders sliding against AISI 440C, stainless-steel disks at a pressure of $10^{-9}$ torr $\left(1.33 \times 10^{-7} \mathrm{~N} / \mathrm{m}^{2}\right.$ ). These data indicated comparable friction coefficients (from 0.15 to $0.30)$ but almost two orders of magnitude higher wear for the unfilled PTFE riders. The filler materials added to the PTFE in various weight percentages were $\mathrm{MoS}_{2}$, glass fibers, copper, and silver.

In bearing applications where solid, self-lubricating materials are used, the retainer not only functions to space the rolling elements equally but also to provide the lubricant at the load-carrying surfaces. The lubrication technique for a ball bearing operating with a self-lubricating retainer is illustrated in figure 1 . Thin films of retainer material are transferred from the retainer pockets to the balls and subsequently to the race grooves. This film transfer mechanism is described in detail in reference 8. 


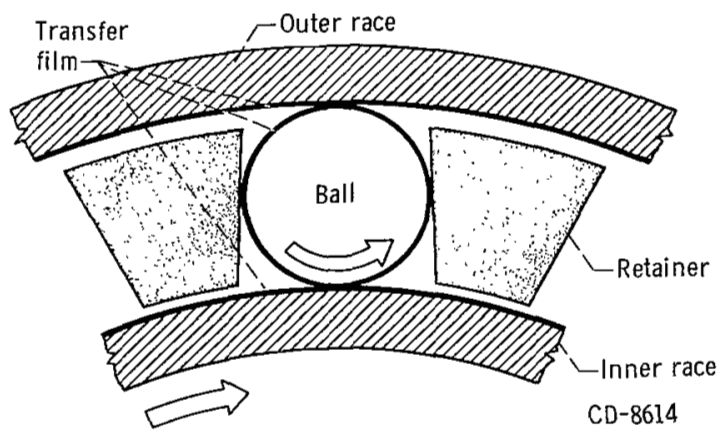

Figure 1. - Film transfer mechanism

This investigation was conducted (1) to determine, in vacuum, the lubricating capability of several filled PTFE retainer materials by measurement of bearing torque and (2) to determine whether varying the percentage additions of glass, $\mathrm{MoS}_{2}$, and/or bronze to the PTFE material influences bearing operation. The lubricating capability of the retainer materials was evaluated in 20-millimeter-bore, size-204 ball bearings operating at ambient pressures of approximately $10^{-6}$ torr $\left(1.33 \times 10^{-4} \mathrm{~N} / \mathrm{m}^{2}\right)$, at a speed of $3600 \mathrm{rpm}$, and at thrust loads of 35 to 100 pounds (156 to $445 \mathrm{~N}$ ) for 1-hour periods.

\section{APPARATUS}

\section{Bearing Test System}

A cutaway view and a cross section of the test-bearing arrangement are shown in figure 2. The test bearing was operated in vacuum and loaded axially by pressurizing the load bellows with compressed air. A stainless-steel wire, connecting the load bellows and the bearing housing, transfers the load. The load bellows was calibrated with a strain-gage ring. The load capacity of the system was approximately 200 pounds $(890 \mathrm{~N})$.

The test-bearing shaft was driven by a $1 / 4$-horsepower (186-W) canned induction motor located inside the bell jar, which rotated the test shaft at a nominally constant speed of $3600 \mathrm{rpm}$. A magnetic speed pickup was used to monitor the motor speed.

The test shaft was mounted vertically and supported by the drive-motor bearings. The drive-motor bearings and the stator were oil-cooled to prevent overheating in vacuum.

A thermocouple welded in the bearing housing and pressed against the outer race of the test bearing was used to indicate the bearing temperature (fig. 2(b)). The thermocouple output was continuously recorded on a strip-chart recorder. 


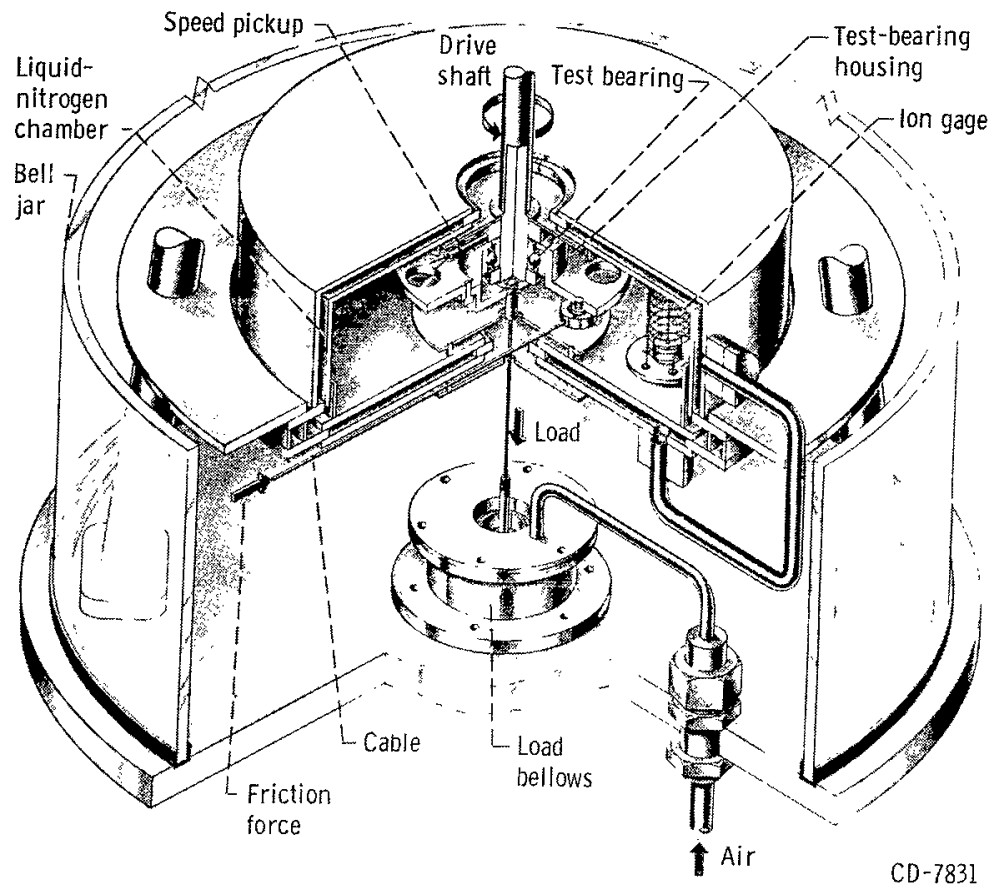

(a) Cutaway view.

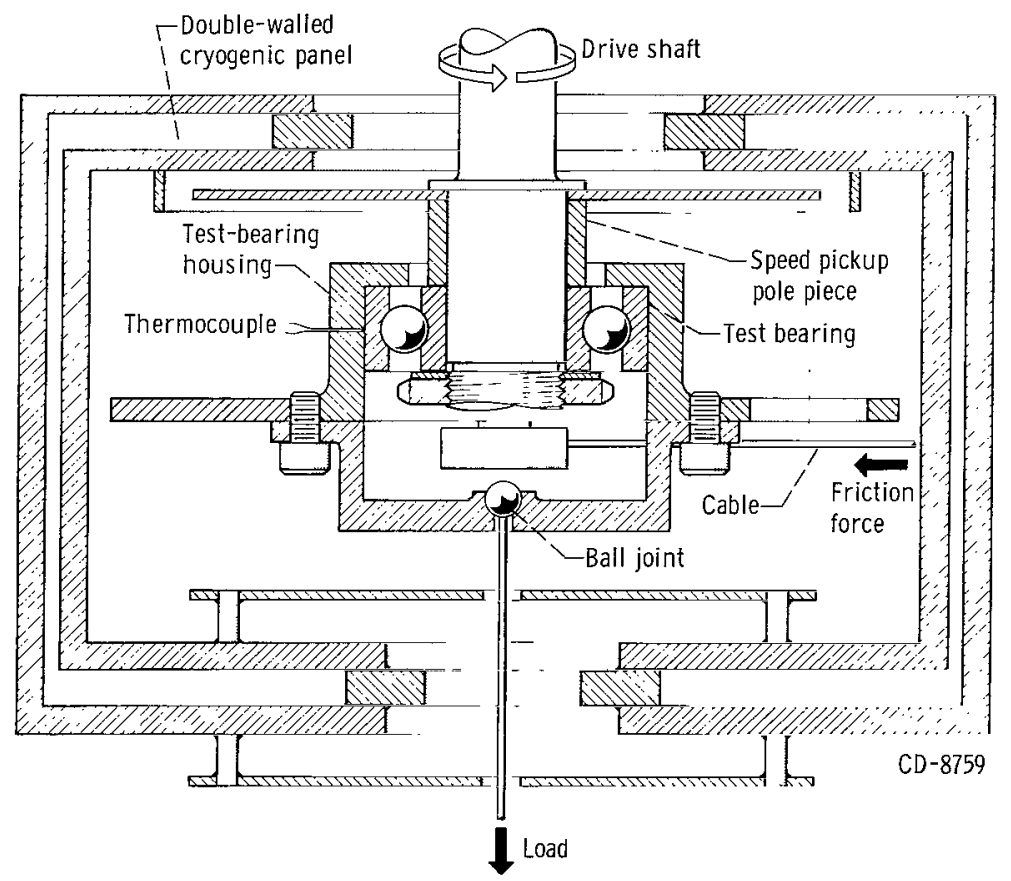

(b) Test-bearing mounting and double-walled chamber.

Figure 2. - Test apparatus. 


\section{Vacuum System}

The test apparatus was mounted in an 18 -inch- $(46-\mathrm{cm})$ diameter bell-jar vacuum system using a 15 -cubic-foot-per-minute $\left(7.1 \times 10^{-3} \mathrm{~m}^{3} / \mathrm{sec}\right)$ mechanical forepump and a 4-inch- (10-cm) diameter oil-diffusion pump. The diffusion pump has a water-cooled baffle and a liquid-nitrogen cold trap. The test-bearing housing was mounted inside a double-walled panel through which liquid nitrogen was circulated (fig. 2(b)). This cryogenic panel was designed to capture backstreaming diffusion-pump oil vapors, as well as lubricant evaporating from the bearing.

The cooling-chamber design simulated the environment of outer space, where a molecule of evaporated lubricant would not be reflected back to the bearing. The pressure measurements in the system were made with a hot-cathode, nude ionization gage mounted inside the double-walled liquid-nitrogen chamber (fig. 2(a)).

A force transducer connected to the bearing housing measured the test-bearing torque. The transducer consisted of an accurately machined cantilever beam and a capacitance probe. The capacitance readout instrument had voltage output proportional to the beam deflection. This output was fed into a strip-chart recorder. The bearing torque could be measured with an accuracy of 0.07 inch-ounce $(0.05 \mathrm{~cm}-\mathrm{N})$.

\section{MATERIALS}

\section{Test Bearings}

All runs were made with size-204 (20-mm-bore) ball bearings fabricated from AISI $440 \mathrm{C}$ stainless steel. The balls and races had a nominal Rockwell $\mathrm{C}$ hardness of 63. One shoulder on the outer race was relieved to make the bearings separable. The inner - and outer-race curvatures were 0.52 , and the average radial clearance was 0.0022 inch $(0.0056 \mathrm{~cm})$.

\section{Test-Bearing Retainers}

The bearing retainers were fabricated from materials containing various percentages of PTFE, glass fibers, $\mathrm{MoS}_{2}$, and bronze. Seven retainer-material compositions, containing the four constituents in the following weight percentages, were investigated: (1) 100 percent PTFE; (2) 85 percent PTFE and 15 percent glass fibers; (3) 80 percent PTFE, 15 percent glass, and 5 percent $\mathrm{MoS}_{2}$; (4) 70 percent PTFE and 30 percent bronze; (5) 90 percent PTFE, 5 percent glass fibers, and 5 percent $\mathrm{MoS}_{2}$; (6) 90 percent 


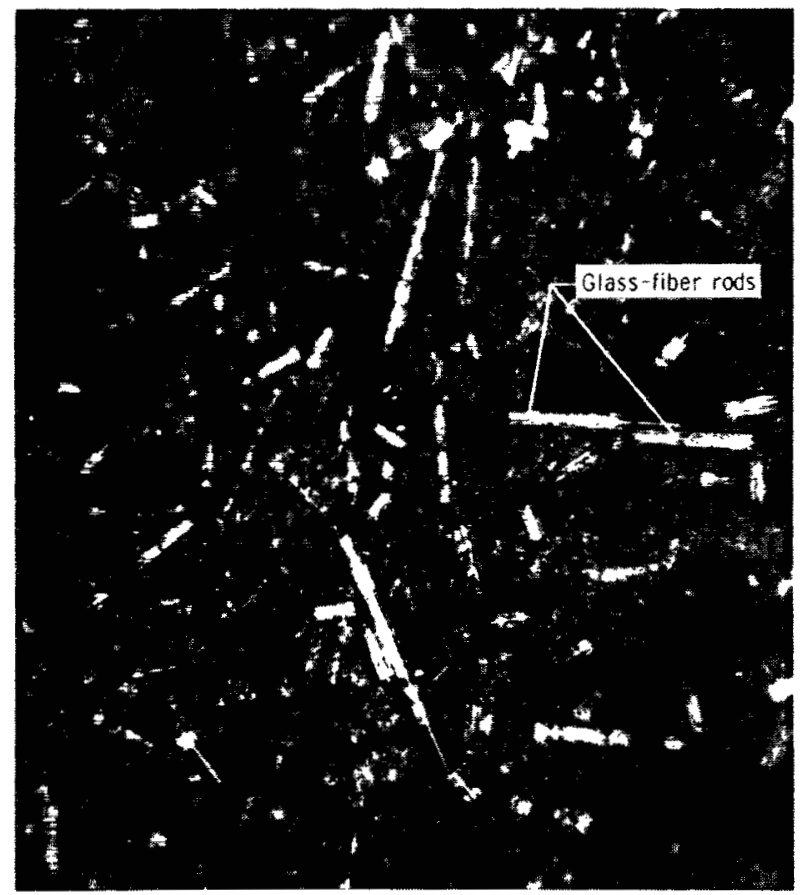

(a) Retainer material 2; 85 percent PTFE and 15 percent glass fibers.

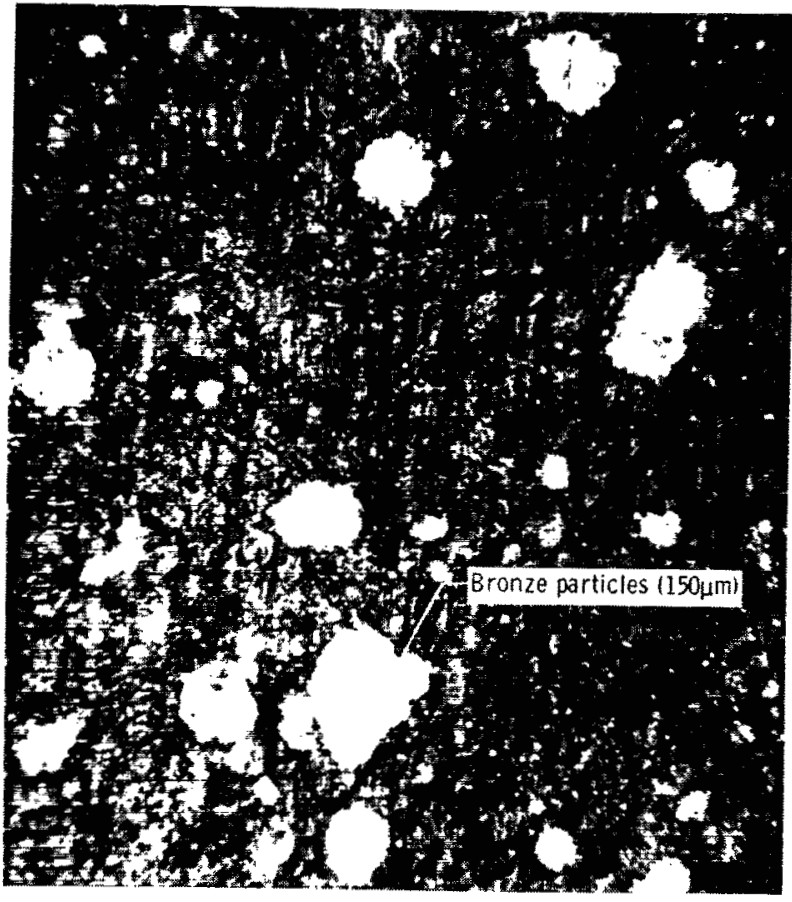

(c) Retainer material 4; 70 percent PTFE and 30 percent bronze powder.

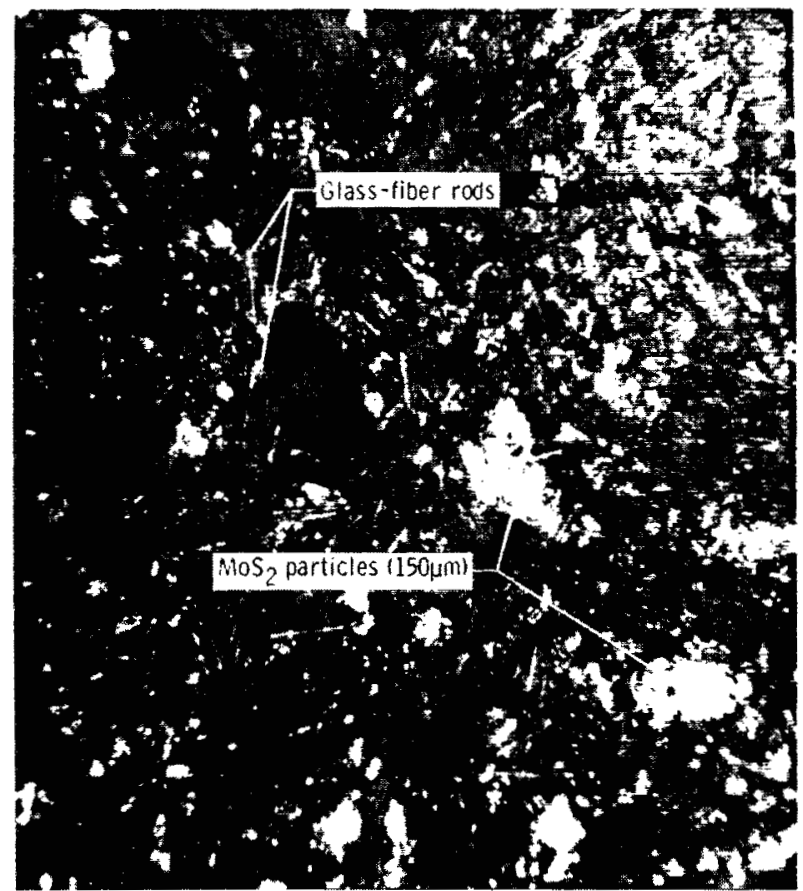

(b) Retainer material 3; 80 percent PTFE, 15 percent glass fibers, and 5 percent MoS$_{2}$.

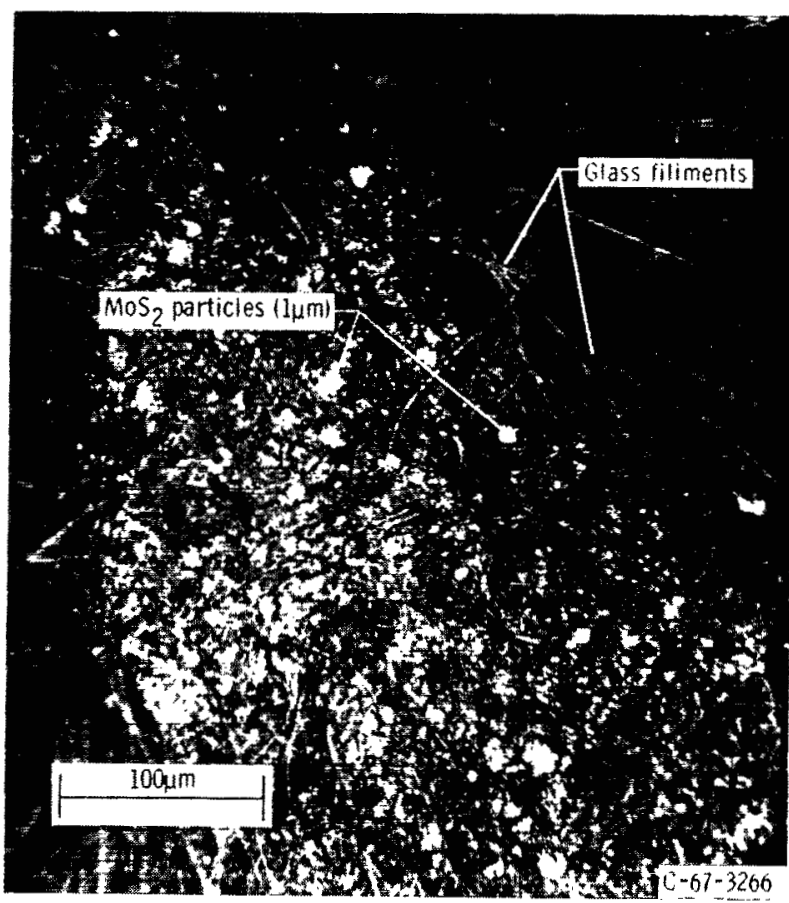

(d) Retainer material 7; 70 percent PTFE, 15 percent glass fibers, and 15 percent $\mathrm{MOS}_{2}$.

Figure 3. - Structure of four self-lubricating retainer materials. 
TABLE I. - SUMMARY OF BEARING TEST RESULTS

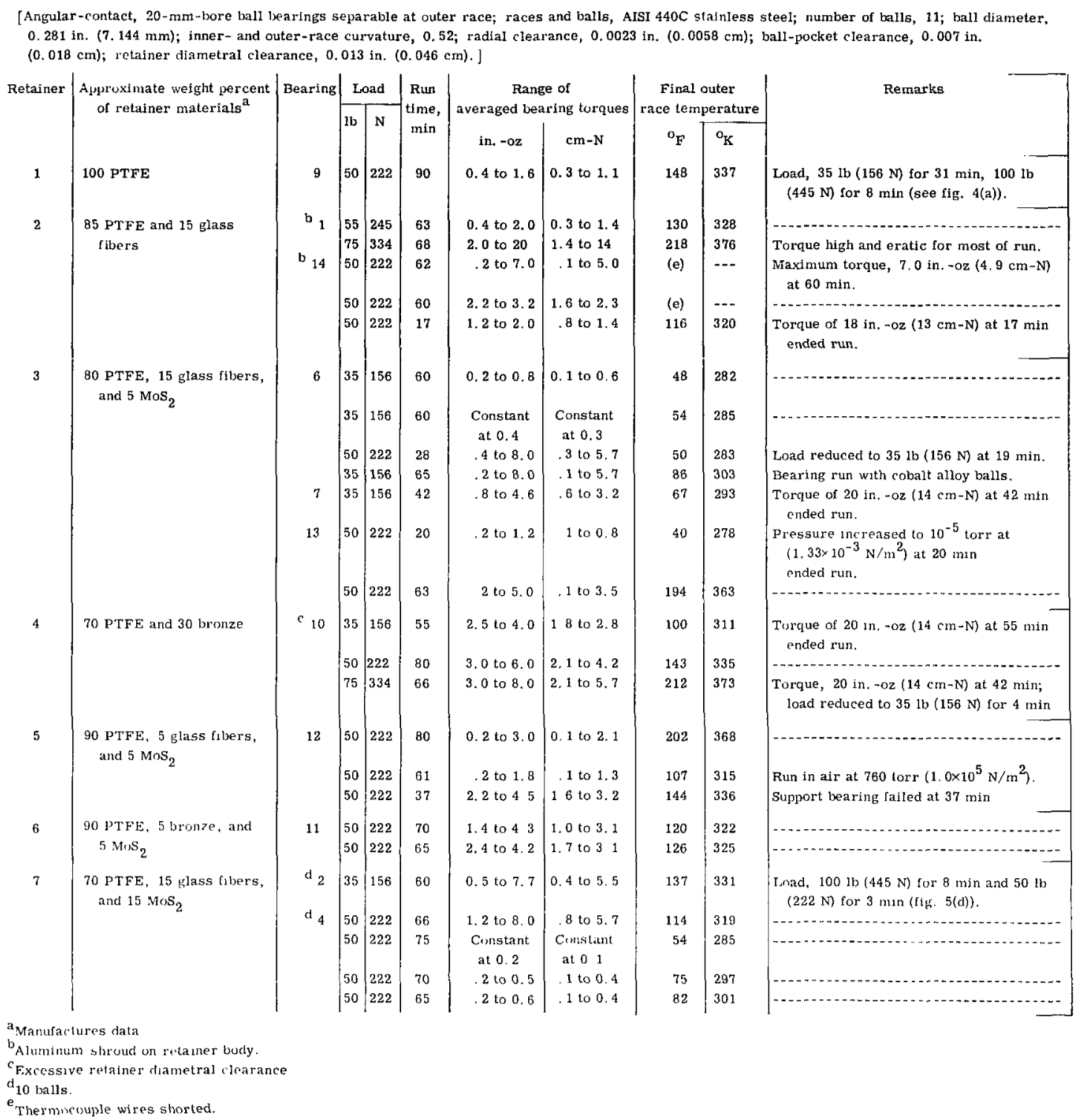

PTFE, 5 percent bronze, and 5 percent $\mathrm{MoS}_{2}$; and (7) 70 percent PTFE, 15 percent glass fibers, and 15 percent $\mathrm{MoS}_{2}$.

Although it is a well-known solid lubricant, PTFE cannot be used as a selflubricating retainer material in its pure form. It has inherently poor strength properties, a tendency to cold flow under load, and a low coefficient of thermal conductivity. Therefore, PTFE must be compounded with filler materials (additives) to provide the required physical properties and good wear life as a retainer material (ref. 9). Glassfiber fillers greatly improve the mechanical strength of PTFE material. Additions of $\mathrm{MoS}_{2}$ increase the material hardness because of the decrease in the percentage of PTFE. 
An increase in material hardness usually improves its wear resistance. Generally, $\mathrm{MoS}_{2}$ is added in small percentages and is used in conjunction with other fillers, such as glass fibers or bronze. Materials with bronze fillers showed higher hardness and improved thermal conductivity and strength above that of the pure PTFE material. The improvements in mechanical and physical properties provided by these and other fillers in PTFE material are described in more detail in reference 9.

The structures of four of the filled PTFE materials evaluated as self-lubricating retainers in this study are illustrated in figure 3. Figure 3(a) shows an 85-percentPTFE and 15-percent-glass-fiber material composed of rod-shaped glass fibers in a PTFE matrix. Figure 3(b) shows an 80-percent-PTFE, 15-percent-glass-fiber, and 5 -percent- $\mathrm{MoS}_{2}$ material also with rod-shaped glass fibers and large-particle-size (approx. $150 \mu \mathrm{m}$ ) $\mathrm{MoS}_{2}$ in the PTFE matrix. Figure 3(c) illustrates a 70-percent-PTFE and 30-percent-bronze material with bronze particles (approx. $150-\mu \mathrm{m}$ size) added to a PTFE matrix. In figure 3(d), a 70-percent-PTFE, 15-percent-glass-fiber, and 15percent-MoS 2 material is shown. The glass fibers appear as thin filaments and the small $\mathrm{MoS}_{2}$ particles (approx. 1- $\mu \mathrm{m}$ size) are blended with the PTFE resin to form a homogeneous material. This material is fabricated by a special process, similar to that used in paper production (ref. 10).

All retainers evaluated were one-piece machined construction and were inner-race located. The average retainer diametral clearance was 0.013 inch $(0.046 \mathrm{~cm})$, and the average ball-pocket clearance was 0.007 inch $(0.018 \mathrm{~cm})$ (see table I).

\section{PROCEDURE}

\section{Test Procedure}

The balls, race sets, and retainers were degreased initially in a solvent $(1,1,1$ trichloroethane), inspected, and measured. After measuring, the test-bearing components were then recleaned in three solvents $(1,1,1$-trichloroethane, acetone, and alcohol) prior to installation.

The test bearing was installed, and the test chamber was pumped to the operating

pressure of approximately $10^{-6}$ torr $\left(1.33 \times 10^{-4} \mathrm{~N} / \mathrm{m}^{2}\right)$ with liquid nitrogen circulating through the double-walled chamber. The torque-measuring system was set at zero, the drive motor was started, and the bearing was operated at an initial load of approximately 35 pounds $(156 \mathrm{~N})$. After approximately 5 minutes of operation, the test load was applied. The bearing was operated at this test condition for 1 hour unless the torque exceeded 20 inch-ounces $(14.1 \mathrm{~cm}-\mathrm{N})$, in which case the test was terminated prematurely. After each test, a visual inspection of the bearing components was performed at a magnifica- 
tion of 15 for indications of film transfer or surface damage on the races and balls, as well as for retainer wear.

\section{Torque Data Reduction}

The original torque traces were reduced by an averaging technique in order to evaluate bearing performance as determined by torque readout. The average torque value for a 5-minute interval was calculated and plotted. (This technique is similar to that described in ref. 1.)

For purposes of comparison, a torque of 8.0 inch-ounces $(5.6 \mathrm{~cm}-\mathrm{N})$ corresponds to a friction coefficient of 0.025 at a 50-pound $(222-\mathrm{N})$ load and 0.013 at a 100 -pound (445-N) load. The latter value is approximately 10 times greater than a friction coefficient for a continuously oil-lubricated ball bearing operating in air at the same load. As a control, an unlubricated bearing with a cotton phenolic retainer was run in this system at 35 -pound $(156-N)$ load (ref. 1). The bearing torque reached 20 inch-ounces $(14 \mathrm{~cm}-\mathrm{N})$ within 3 minutes.

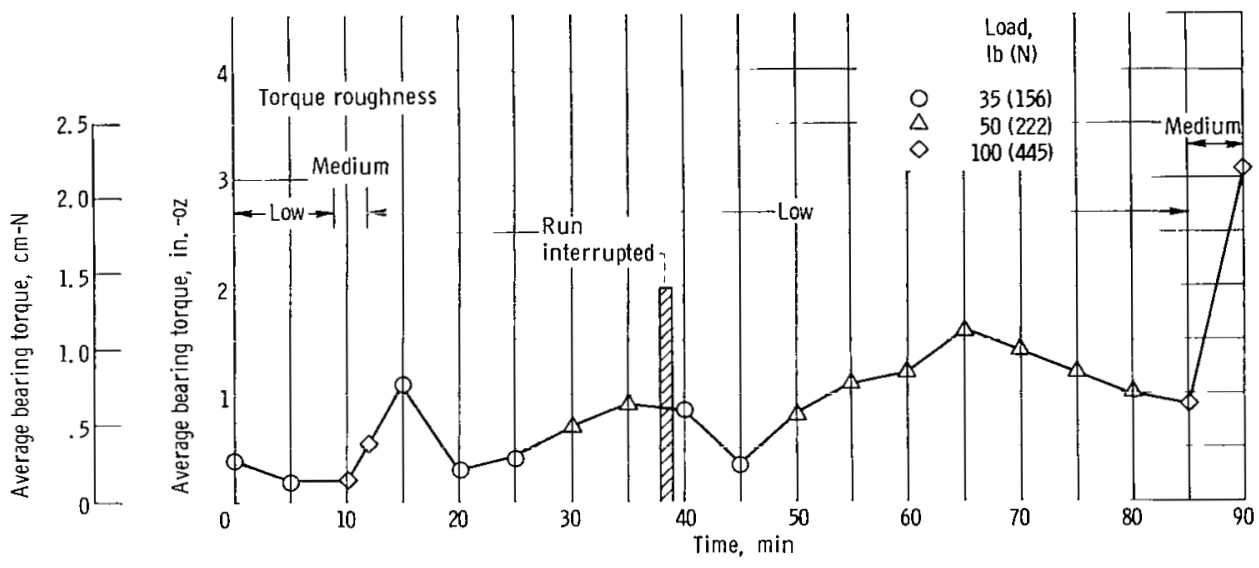

(a) Average bearing torque.

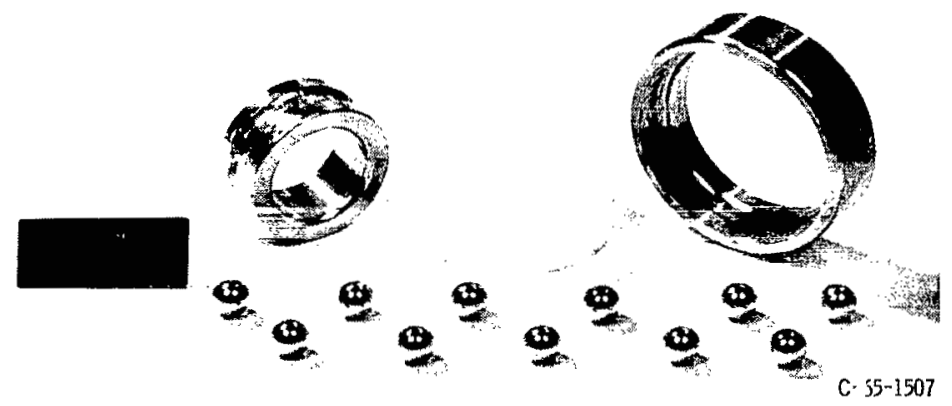

(b) Postrun condition.

Figure 4. - Bearing 9 with a 100-percent-PTFE retainer. Test conditions: axial load, 35, 50, and 100 pounds $(156,222$, and $445 \mathrm{~N})$; speed, $3600 \mathrm{rpm}$; pressure, $10^{-6}$ to $10^{-7}$ torr $\left(1.33 \times 10^{-4}\right.$ to $1.33 \times 10^{-5} \mathrm{~N} / \mathrm{m}^{2}$. 
Another characteristic of the original torque trace, which is filtered out by the averaging process, is the torque roughness. Roughness is defined as the peak-to-peak amplitude of the bearing torque excursions (ref. 1). The magnitude of the roughness can provide, on a relative scale, a measure of lubricating effectiveness of the transfer film on the bearing load-carrying surfaces. The torque roughness was classified into the following three levels: low (L), from 0 to 1.0 inch-ounce $(0.7 \mathrm{~cm}-\mathrm{N})$; moderate $(\mathrm{M})$, from 1.0 to 7.0 inch-ounces $(0.7$ to $4.9 \mathrm{~cm}-\mathrm{N})$; and high $(\mathrm{H})$, greater than 7.0 inch-ounces $(4.9 \mathrm{~cm}-\mathrm{N})$. These roughness levels are shown at the top of the average torque - time plots for the various materials in figures $4(\mathrm{a})$ and 6 .

\section{RESULTS AND DISCUSSION}

The results of the bearing runs are summarized in table I. The range of averaged torque values, the running time, and the final temperature measured at the bearing outer race are given for each run.

\section{Torque Histories of Filled PTFE Retainer Materials}

100-percent-PTFE material. - A 100-percent-PTFE retainer material (bearing 9, table I) was run at loads of 35,50 , and 100 pounds (156, 222, and $445 \mathrm{~N}$ ) to establish a base-line torque for comparing the filled PTFE materials. The average bearing torque plotted against running time is shown in figure 4(a). The torque did not exceed 1.6 inch-ounces $(1.1 \mathrm{~cm}-\mathrm{N})$ for 85 minutes. During the last 5 minutes of the run, when the load was again increased to 100 pounds $(445 \mathrm{~N})$, the torque increased to 3.1 inchounces $(2.3 \mathrm{~cm}-\mathrm{N})$.

Bearing 9 after test is shown in figure 4(b). Large amounts of wear debris from the retainer are evident on the bearing races. It was concluded, therefore, that although the bearing torque at the three loads was satisfactory, the wear of the 100-percent-PTFE material was unacceptably high.

Initial runs with filled PTFE materials. - Initial runs were made with the four basic filled PTFE materials illustrated in figure 3. The bearings were run at loads of 35,50 , and 55 pounds $(156,222$, and $245 \mathrm{~N})$. The average torque values are shown in figure 5 . Bearings 1 and 14 with 85 percent PTFE (fig. 5(a)) and bearings 7 and 13 with 80 percent PTFE (fig. 5(b)) in the retainer material had lower average torque values for the runs than did those bearings having retainers with 70 percent PTFE (bearing 10 and bearings 2 and 4, figs. 5(c) and (d), respectively). The average torque values of bearings 1, 7, and 14 compared favorably with the torque of bearing 9 which had a 100-percent-PTFE retainer (fig. 4(a)). Bearing 2 (fig. 5(d)) with a 70-percent-PTFE, 15-percent-glass- 


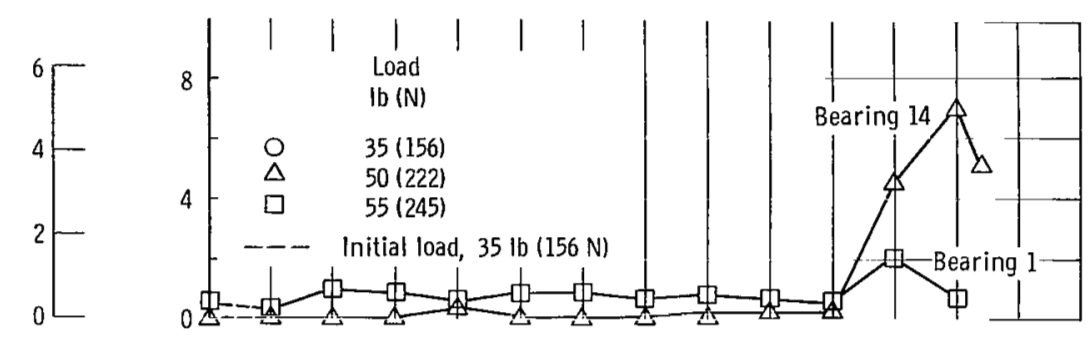

(a) 85 Percent PTFE and 15 percent glass fibers.
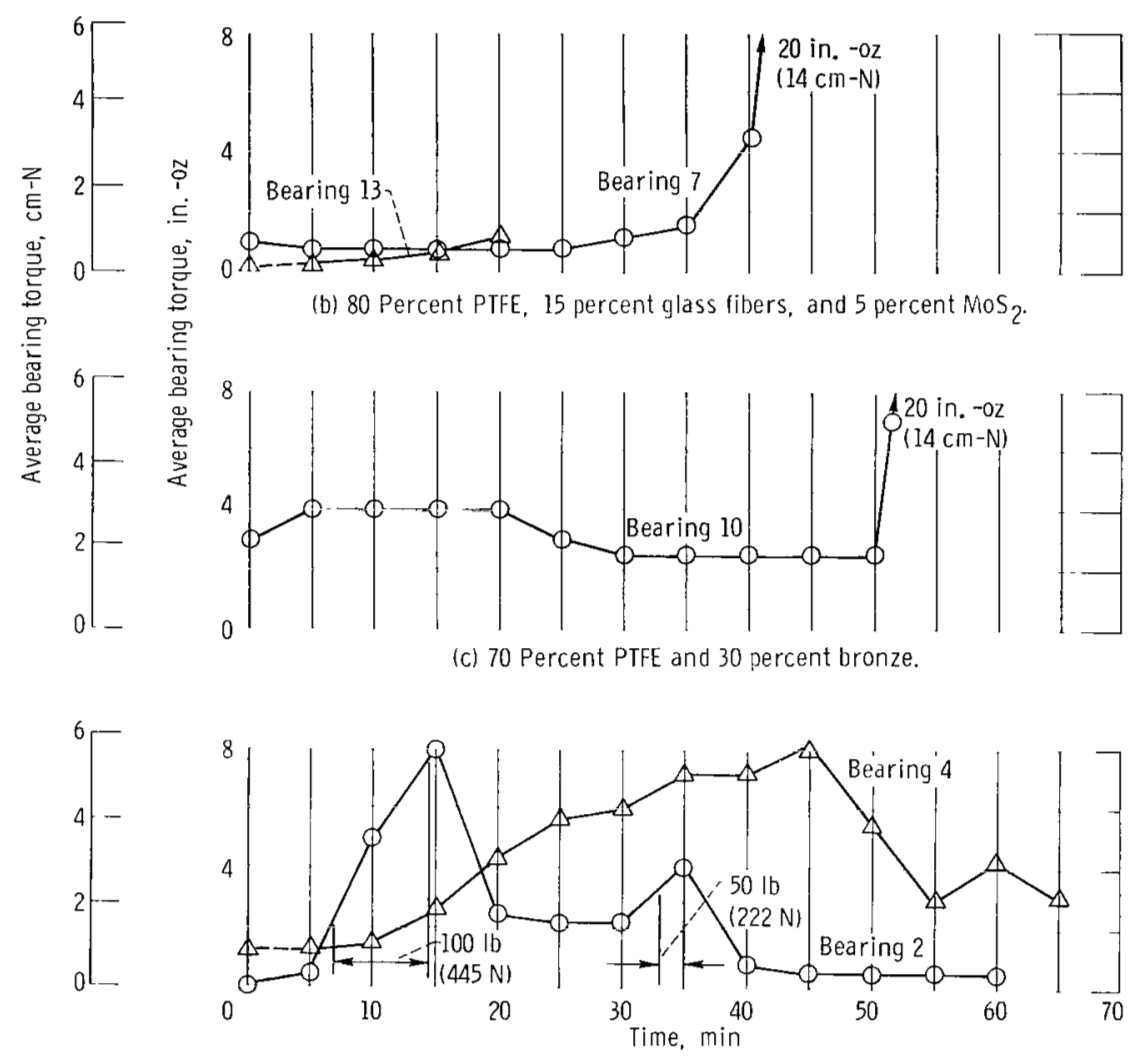

(d) 70 Percent PIFE, 15 percent glass fibers, and 15 percent MoS $_{2}$.

Figure 5. - Initial runs with four filled PTFE retainers. Speed, $3600 \mathrm{rpm}$; pressure, $10^{-6}$ to $10^{-7}$ torr $\left(1.33 \times 10^{-4}\right.$ to $\left.1.33 \times 10^{-5} \mathrm{~N} / \mathrm{m}^{2}\right)$.

fiber, and 15-percent-MoS 2 retainer, running at a 35-pound (156-N) load, reflected high torque when loads of 50 and 100 pounds (222 and $445 \mathrm{~N}$ ) were applied for short time intervals. Bearings 7 and 10 had a rapid rise in torque to 20 inch-ounces $(14 \mathrm{~cm}-\mathrm{N})$ that resulted in prematurely ending the runs at 42 and 55 minutes, respectively. The run for bearing 13 was ended at 20 minutes because of a decade rise in chamber pressure (to $\left.10^{-5} \operatorname{torr}\left(1.33 \times 10^{-3} \mathrm{~N} / \mathrm{m}^{2}\right)\right)$.

Comparison of average torque at 50-pound $(222-\mathrm{N})$ loads. - Four bearings, one each with the four basic filled PTFE materials of figure 5, were rerun at 50-pound (222-N) 


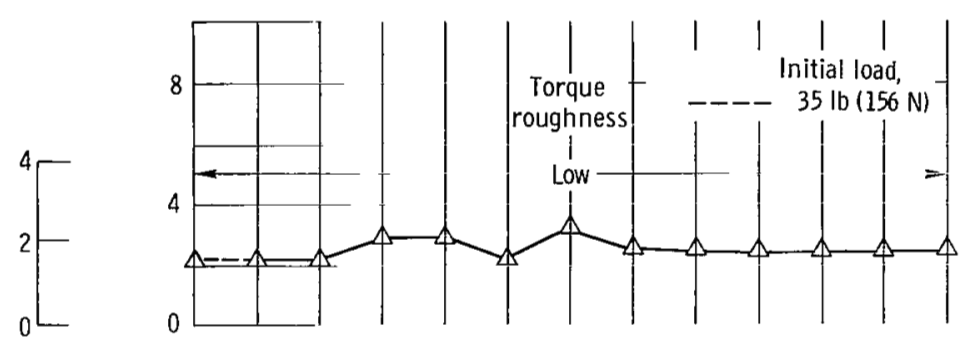

(a) Bearing 14; 85 percent PTFE and 15 percent glass fibers.

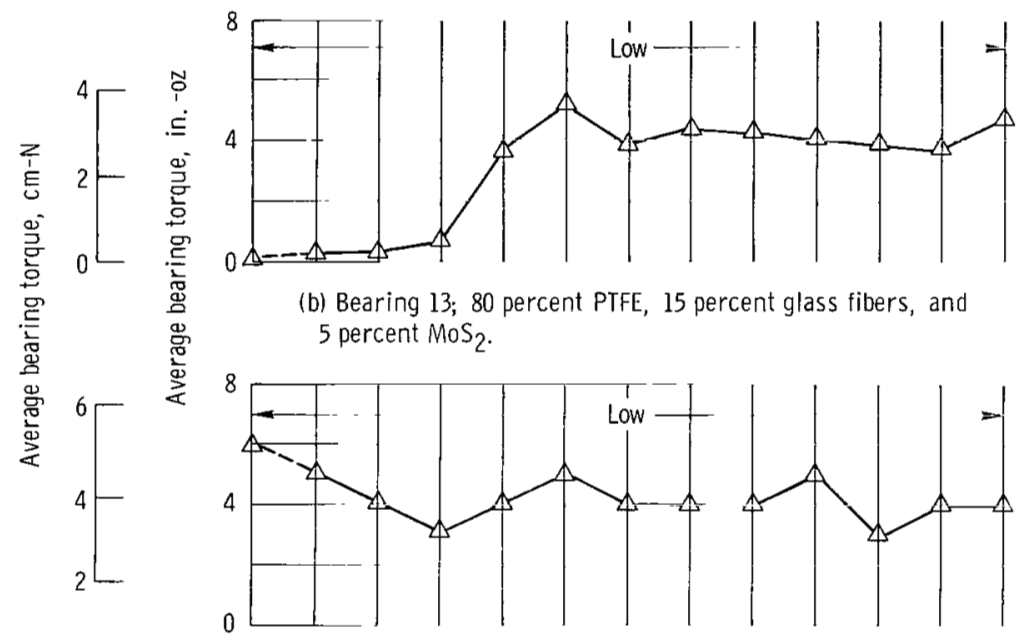

(c) Bearing 10; 70 percent PTFE and 30 percent bronze.
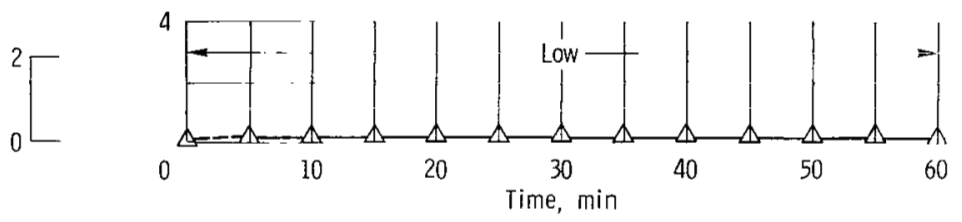

(d) Bearing 4; 70 percent PTFE, 15 percent glass fibers, and 15 percent $\mathrm{MOS}_{2}$.

Figure 6. - Comparison of average bearing torque for four retainer materials. Load, 50 pounds ( $222 \mathrm{~N}$ ); speed, $3600 \mathrm{rpm}$; pressure, $10^{-6}$ to $10^{-7}$ torr $\left\{1.33 \times 10^{-4}\right.$ to $\left.1.33 \times 10^{-5} \mathrm{~N} / \mathrm{m}^{2}\right\}$.

loads. Their torque values for the first 60 minutes of the runs are compared in figure 6 . Bearing 4, with a 70-percent-PTFE, 15-percent-glass-fiber, and 15-percent-MoS 2 retainer (fig. 6(d)), had an extremely low and constant level of torque for the entire run. In this second run, bearing 4 demonstrated a marked improvement in average torque over the initial run shown in figure $5(d)$.

Effect of 5-percent-MoS 2 additions to glass-fiber-filled PTFE material. - In figure 5 (initial runs) and figure 6 (second runs), bearing 14, with an 85-percent-PTFE and 15-percent-glass-fiber retainer, is compared with bearing 13 , with an 80 -percentPTFE, 15-percent-glass-fiber, and 5-percent-MoS ${ }_{2}$ retainer, at a 50-pound (222-N) 


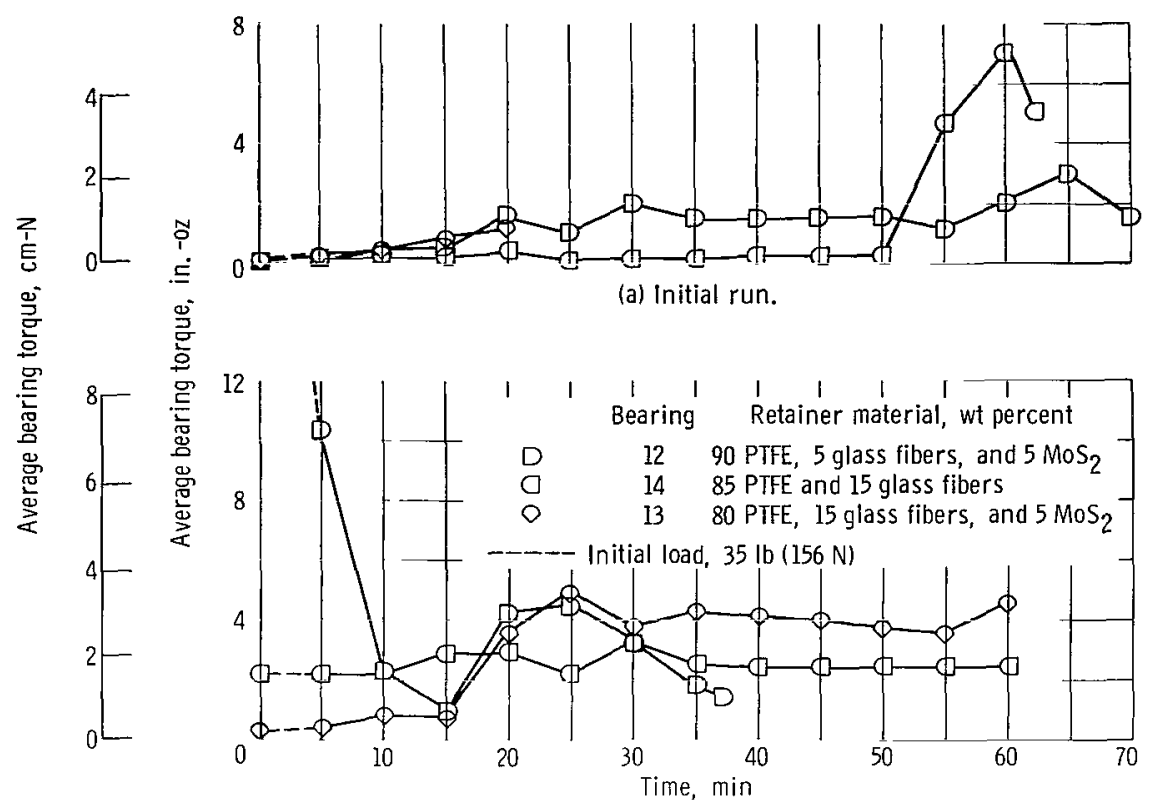

(b) Second run.

Figure 7. - Comparison of average bearing torque for three PTFE filled retainer materials using glass-fiber and $\mathrm{MOS}_{2}$ additions. Load, 50 pounds $(222 \mathrm{~N})$; speed, 3600 rom; pressure, $10^{-6}$ to $10^{-7}$ torr $\left(1.33 \times 10^{-4}\right.$ to $\left.1.33 \times 10^{-5} \mathrm{~N} / \mathrm{m}^{2}\right)$.

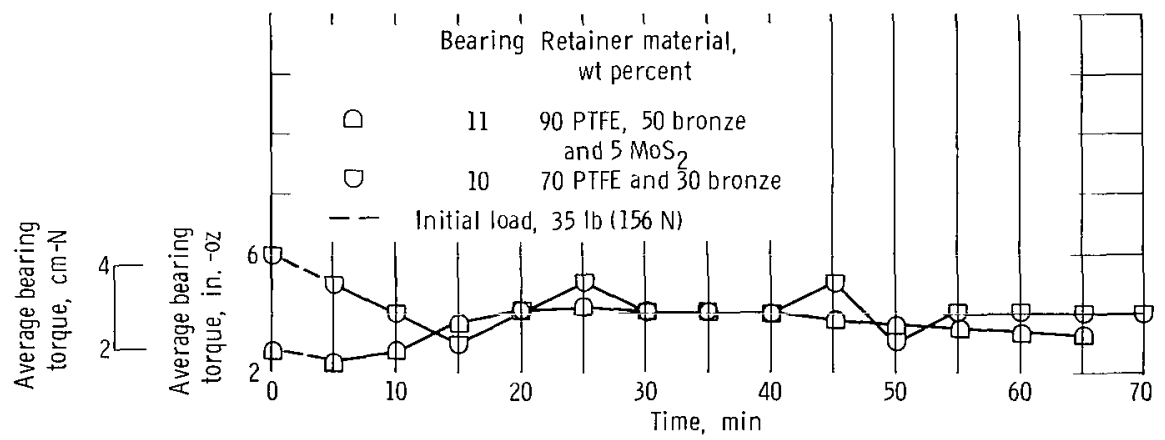

Figure 8. - Comparison of average bearing torque for two bronze-filled PTFE retainer materials. Load, 50 pounds $(222 \mathrm{~N})$; speed, $3600 \mathrm{rpm}$; pressure, $10^{-6}$ to $10^{-7}$ torr $\left(1.33 \times 10^{-4}\right.$ to $\left.1.33 \times 10^{-5} \mathrm{~N} / \mathrm{m}^{2}\right)$.

load. Bearing 12 , with a 90-percent-PTFE, 5-percent-glass-fiber, and 5-percent-MoS 2 retainer, was also run at a 50-pound $(222-\mathrm{N})$ load. The average torque values of these three bearings are compared in figure 7. In both the initial (fig. 7(a)) and second runs (fig. 7(b)), no appreciable difference in bearing torque between the three retainer materials is apparent.

Subsequent to the initial run (fig. $7(\mathrm{a})$ ), bearing 12 was run in air (760-torr $\left(1.0 \times 10^{5}-\mathrm{N} / \mathrm{m}^{2}\right)$ pressure) at a 50 -pound $(222-\mathrm{N})$ load. Figure $7($ b) shows a high start- 
ing torque for bearing 12 in the second run, which was ended prematurely because of a support bearing failure (table I).

Effect of bronze additions to PTFE material. - As previously mentioned, one method of improving wear resistance and thermal properties of PTFE is by the addition of metal fillers such as bronze. This concept was evaluated for two retainer materials with 5 and 30 percent weight additions of bronze powder. The average torque values for bearing 11 , with a 90-percent-PTFE, 5-percent-bronze, and 5-percent-MoS 2 retainer, and for bearing 10, with a 70-percent-PTFE and 30-percent-bronze retainer, are shown in figure 8 . Both bearings were run at a 50-pound (222-N) load. Although bearing 10 did have higher initial torque, the ave rage torque levels for the balance of the run appear similar. No benefit in heat dissipation was noted for these two bronze-filled retainers over other materials run, based on their average bearing torque (fig. 8) or final outer race temperature (table $I$ ).

Bearing restart capability. - Restart capability in a vacuum environment is defined as the ability of a bearing to restart and run at a low torque level after remaining at rest in vacuum for an extended period of time (soaking for 24 hours or longer). Restart capability in a series of consecutive runs was demonstrated with three bearings, as shown in figure 9 .

Bearing 14 was run at a 50-pound (222-N) load for two consecutive runs (fig. $9(\mathrm{a})$ ). In the first run, bearing 14 ran at low torque for 50 minutes. During the last 10 minutes of this run, the torque increased to a maximum of 7 inch-ounces $(4.9 \mathrm{~cm}-\mathrm{N})$. After soaking for approximately 72 hours, the bearing was restarted under load. After restart the torque decreased, and the bearing ran a second hour at a torque level somewhat higher than in the first run.

Bearing 6, shown in figure $9(\mathrm{~b})$, ran at a low torque level for two 1 -hour runs at a 35 -pound $(156-N)$ load. The time between the first two runs was 48 hours; 24 hours after the second run a third run was made at a 50-pound (222-N) load. After approximately 20 minutes at low torque, the torque increased to more than 8 inch-ounces $(5.6 \mathrm{~cm}-\mathrm{N})$ in the next 10 minutes, even though the load was reduced to 35 pounds $(156 \mathrm{~N})$. At 28 minutes, therefore, this run was ended prematurely.

Four consecutive runs, of more than 1 hour each, were made with bearing 4 at 50-pound (222-N) loads, as shown in figure $9(\mathrm{c})$. During the first run the bearing experienced high and erratic torque (also see fig. 5(d)). The high-torque condition during the initial run was attributed to a lack of an adequate lubricating film on the bearing load-carrying surfaces. For the three subsequent runs, however, the torque remained at a low, constant level, indicating that the bearing was now adequately lubricated by the transfer film. The soaking times after the first, second, and third runs were 72,120 , and 24 hours, respectively. Bearing 4, with a 70-percent-PTFE, 15-percent-glass-fiber, and 15-percent- $\mathrm{MoS}_{2}$ retainer, demonstrated the best restart capability of the three 


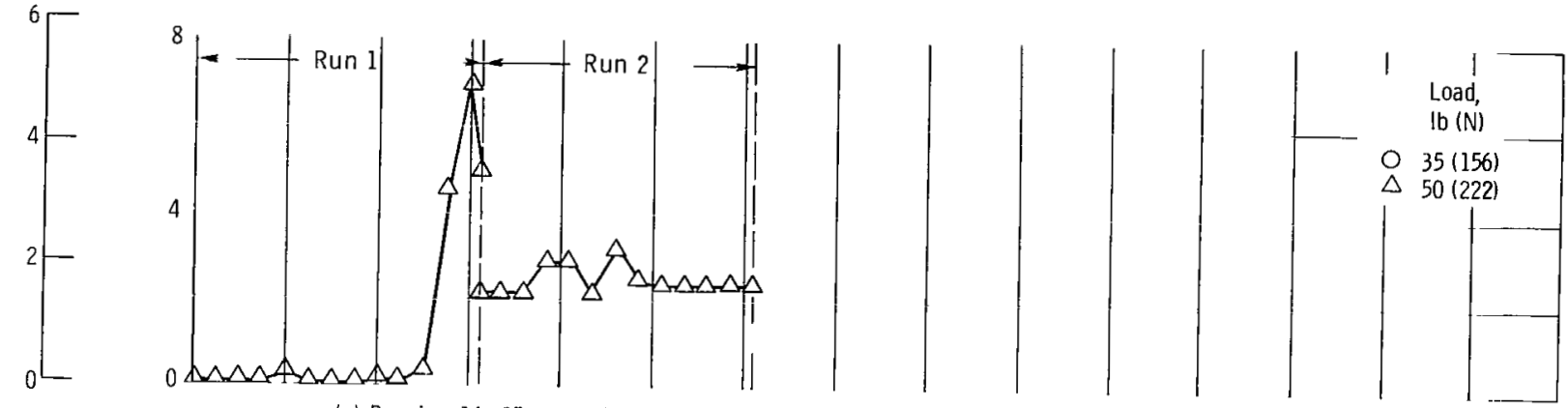

(a) Bearing 14; 85 percent PTFE and 15 percent glass fibers. Soaking time after first run, 72 hours.
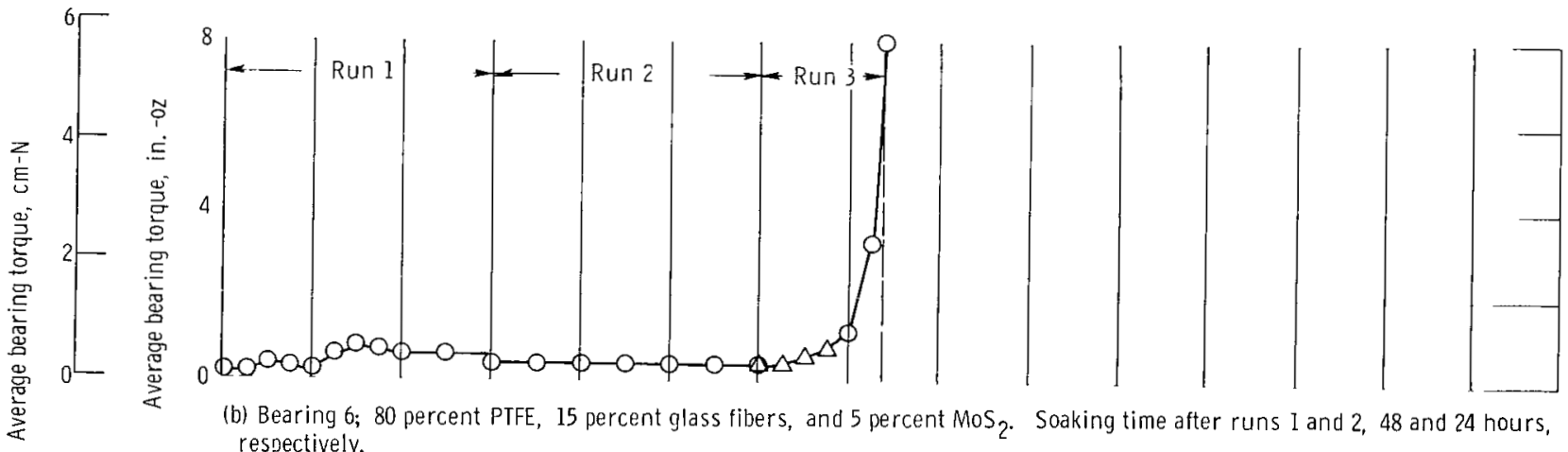

(b) Bearing 6; 80 percent PTFE, 15 percent glass fibers, and 5 percent MoS2. Soaking time after runs 1 and 2, 48 and 24 hours, respectively.

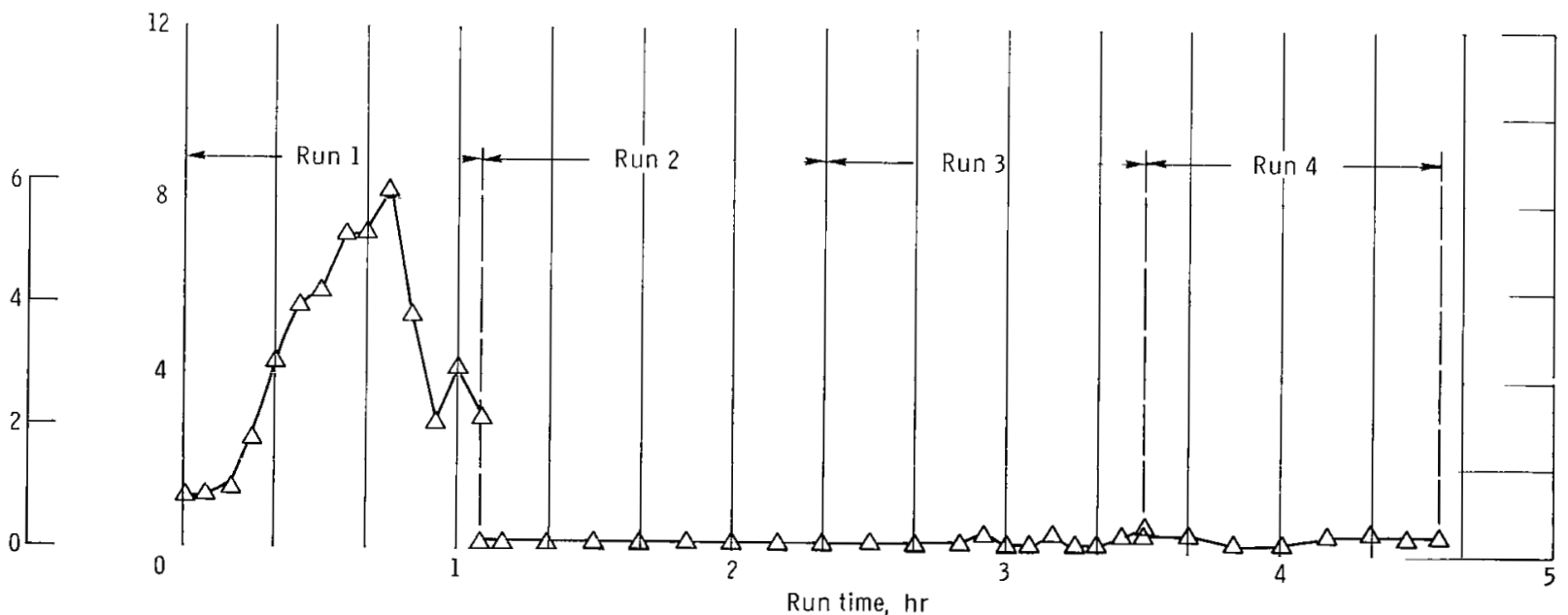

(c) Bearing 4; 70 percent PTFE, 15 percent glass fibers, and 15 percent MoS 2 . Soaking time after runs, 72,120 , and 24 hours, respectively.

Figure 9. - Restart capability of three filled PTFE retainef materials. Speed, $3600 \mathrm{rpm}$; pressure, $10^{-6}$ to $10^{-7}$ torr $\left(1.33 \times 10^{-4}\right.$ to $1.33 \times 10^{-5} \mathrm{~N} / \mathrm{m}^{2}$. 
bearings. Although all other retainer materials lubricated the bearings reasonably well, the best overall performance was achieved with this retainer material. This conclusion is based on the consistently low bearing torque values for this material.

\section{Post-Test Examination of Bearings}

At the end of the test runs, the bearings were examined at a magnification of 15 to determine the extent of retainer wear, transfer films on the ball and race surfaces, and surface damage on the ball and race wear tracks.

All retainers, except the 100-percent-PTFE material, experienced little wear with uniform-width wear bands evident in the ball pockets and on the inner-diameter locating surfaces. The balls and races were coated with a film of transferred retainer material that was visibly evident. The degree of retainer wear and the transfer films on the balls and races are illustrated in figure 10. Bearings 14, 6, and 4 (figs. 10(a), (b), and (d),
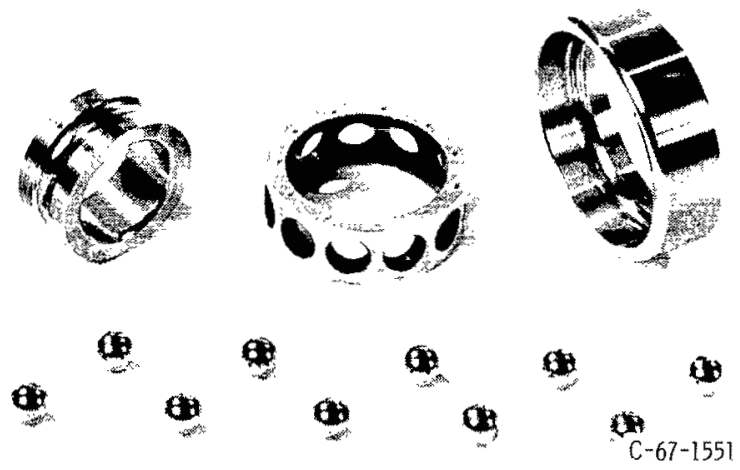

(a) Bearıng 14. Retaıner material, 85 percent PTFE and 15 percent glass fibers; run time, 139 minutes; load, 50 pounds (222N).

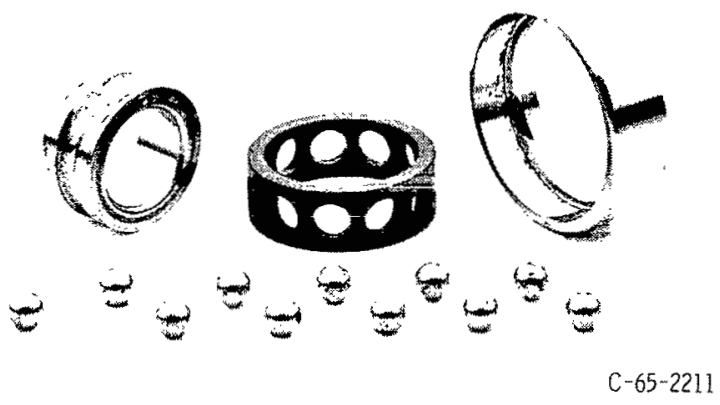

(b) Bearing 6. Retainer material, 80 percent PTFE, 15 percent glass fibers, and 5 percent $\mathrm{MoS}_{3}$; run time, 213 minutes; loads, 35 and 50 pounds (156 and $222 \mathrm{~N}$ ).
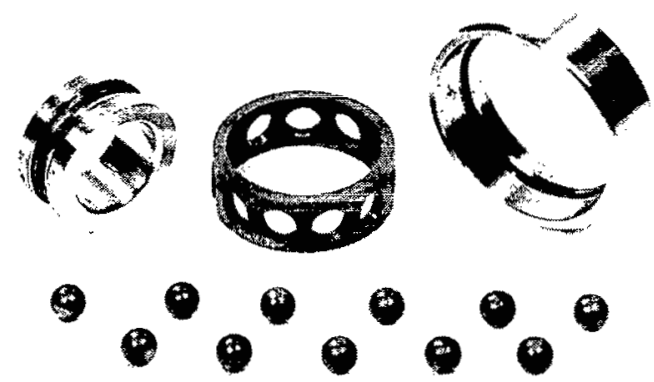

C- $-66-436$

(c) Bearing 10. Retainer material, 70 percent PTFE and 30 percent bronze; run time, 201 minutes; loads, 35, 50, and 75 pounds $(156,222$, and 334N).

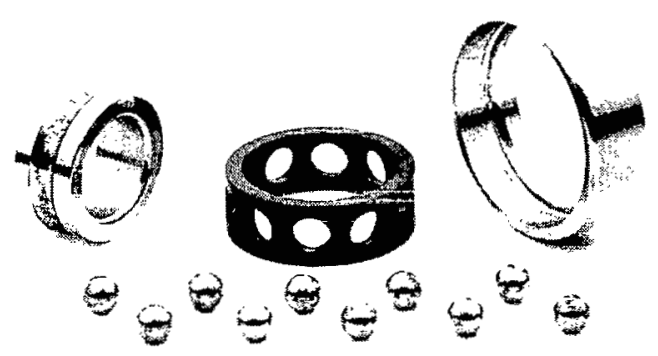

C- $65-2209$

(d) Bearing 4. Retainer material, 70 percent PTFE, 15 percent glass fibers, and 15 percent $\mathrm{MoS}_{2}$; run time, 276 minutes; load, 50 pounds (222N).

Figure 10. - Bearings after testing at speed of $3600 \mathrm{rpm}$ and pressure of $10^{-6}$ to $10^{-7}$ torr $\left(1.33 \times 10^{-4}\right.$ to $\left.1.33 \times 10^{-5} \mathrm{~N} / \mathrm{m}^{2}\right)$. 
respectively) show various amounts of transfer film on the ball and race surfaces. The black flakes on the races may be evidence either of the $\mathrm{MoS}_{2}$ in the material or of decomposition of the PTFE.

Bearing 10 (fig. 10(c)) has darkened balls and wear tracks in the race grooves. The darkened appearance is apparently caused by high bearing torque accompanied by high temperatures within the bearing (see table I).

\section{SUMMARY OF RESULTS}

Seven self-lubricating retainer materials were run in 20-millimeter-bore ball bearings at pressures of $10^{-6}$ torr $\left(1.33 \times 10^{-4} \mathrm{~N} / \mathrm{m}^{2}\right)$. Glass fibers, molybdenum disulfide $\left(\mathrm{MoS}_{2}\right)$, and bronze, added to polytetrafluoroethylene (PTFE) in various weight percentages, were evaluated in the bearing retainers. The lubricating capability of retainer materials was evaluated by measurement of the bearing friction torque in the vacuum environment. The bearings were operated at $3600 \mathrm{rpm}$ at thrust loads from 35 to 100 pounds (156 to $445 \mathrm{~N}$ ) for periods of approximately 1 hour.

The investigation produced the following results:

1. All self-lubricating materials evaluated lubricated the bearings reasonably well in the vacuum environment.

2. The best lubrication was achieved with a 70-percent-PTFE, 15-percent-glassfiber, and 15-percent-MoS 2 retainer material, as determined by the lowest and most consistent values of bearing torque. Initial bearing runs with this material indicated that a run-in period was required before good lubrication could be achieved. A bearing with this retainer material also demonstrated good restart capability.

3. Bearing torque was not markedly improved by the addition of 5 percent MoS $_{2}$ to PTFE glass-fiber-filled retainer materials.

4. Bronze-filled PTFE and bronze-filled PTFE with 5-percent-MoS $\mathrm{S}_{2}$ retainer materials ran at approximately the same torque level as the other filled PTFE materials. However, no benefit in heat dissipation was noted for these bronze-filled retainers.

5. The wear rate of 100-percent-PTFE retainer material was excessive. Therefore, filler additions are necessary to improve wear characteristics.

Lewis Research Center,

National Aeronautics and Space Administration,

Cleveland, Ohio, August 14, 1967, 129-03-13-02-22. 


\section{REFERENCES}

1. Smith, L. Dale; Glenn, Dean C. ; and Scibbe, Herbert W.: Evaluation of Impregnated Lubricants in Ball-Bearing Retainers at $10^{-6}$ torr. NASA TN D-3259, 1966.

2. Bisson, Edmond E.; and Anderson, William J.: Advanced Bearing Technology. NASA SP-38, 1964, pp. 279-283.

3. Buckley, Donald H.; Swikert, Max; and Johnson, Robert L.: Friction, Wear, and Evaporation Rates of Various Materials in Vacuum to $10^{-1} \mathrm{~mm} \mathrm{Hg.} \mathrm{ASLE} \mathrm{Trans.,}$ vol. 5, no. 1, Apr. 1962, pp. 8-23.

4. Buckley, Donald H. ; and Johnson, Robert L.: Evaporation Rates for Various Organic Liquid and Solid Lubricants in Vacuum to $10^{-8}$ Millimeter of Mercury at $55^{\mathrm{O}}$ to $1100^{\mathrm{O}} \mathrm{F}$. NASA TN D-2081, 1963.

5. Clauss, F. J.; and Young, W. C.: Materials for Lubricated Systems. Space Materials Handbook. C. G. Goetzel, J. B. Rittenhouse, and J. B. Singletary, eds., Addison-Wesley Publ. Co., Inc., 1965, pp. 209-296.

6. Buckley, Donald H.; and Johnson, Robert L. : Friction, Wear, and Decomposition Mechanisms for Various Polymer Compositions in Vacuum to $10^{-9}$ Millimeter of Mercury. NASA TN D-2073, 1963.

7. Bowen, Paul H.: Dry Lubricated Bearings for Operation in a Vacuum. ASLE Trans., vol. 5, no. 2, Nov. 1962, pp. 315-326.

8. Brewe, David E.; Scibbe, Herbert W.; and Anderson, William J. : Film-Transfer Studies of Seven Ball-Bearing Retainer Materials in $60^{\circ} \mathrm{R}\left(33^{\circ} \mathrm{K}\right)$ Hydrogen Gas at 0. 8 Million DN Value. NASA TN D-3730, 1966.

9. O'Rourke, J. Tracy: Design Properties of Filled-TFE Plastics. Machine Design, vol. 34 , no. 21, Sept. 13, 1962, pp. 172-180.

10. Greenman, Norman L.: New Reinforced TFE Plastics Resist Cold Flow. Mat. Des. Eng., vol. 50, no. 4, Oct. 1959, pp. 98-101. 


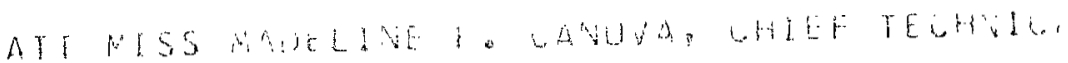

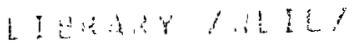

"The aeronautical and space activities of the United States shall be conducted so as to contribute... to the expansion of buman knowledge of phenomena in the atmosphere and space. The Administration shall provide for the widest practicable and appropriate dissemination of information concerning its activities and the results thereof."

-National Aeronautics and Space Act of 1958

\section{NASA SCIENTIFIC AND TECHNICAL PUBLICATIONS}

TECHNICAL REPORTS: Scientific and technical information considiered important, complete, and a lasting contribution to existing knowledge.

TECHNICAL NOTES: Information less broad in scope but nevertheless of importance as a contribution to existing knowledge.

TECHNICAL MEMORANDUMS: Information receiving limited distribution because of preliminary data, security classification, or other reasons.

CONTRACTOR REPORTS: Scientific and technical information generated under a NASA contract or grant and considered an important contribution to existing knowledge.

TECHNICAI TRANSLATIONS: Information published in a foreign language considered to merit NASA distribution in English.

SPECIAL PUBLICATIONS: Information derived from or of value to NASA activities. Publications include conference proceedings, monographs, data compilations, handbooks, sourcebooks, and special bibliographies.

TECHNOLOGY UTILIZATION PUBLICATIONS: Information on technology used by NASA that may be of particular interest in commercial and other non-aerospace applications. Publications include Tech Briefs, Technology Utilization Reports and Notes, and Technology Surveys.

Details on the availability of these publications may be obtained from:

SCIENTIFIC AND TECHNICAL INFORMATION DIVISION 